\title{
Capítulo 29
}

\section{Ideologias desencontradas na Jazz Metropolis: a cultura do design no "adapting reúso"}

Rui Roda

A relação entre as dinâmicas de uso informal da cidade e as ideologias de uma cultura do projeto em Design, de forma aplicada ou em tons de meta-ensaios, resultaram em dois importantes vetores produtores de um fértil plâncton de oportunidades para um profícuo diálogo, que aqui se expressa, mas que ao longo do tempo nunca se concretizou. Ambiciona-se a partir desta realidade, promover um espaço de reflexão dedicado à história destes desencontros, destas duas dimensões: a que produziu soluções informais em um contexto de emergência aplicada à refuncionalização da cidade; e uma dimensão antropológica do Design que, na sua ambição, declarava uma autonomia no interior dos espaços construídos da cidade.

É neste contexto que ouso construir a metáfora resultante de Jazz com $\mathrm{Me}$ tropolis. Conjuntamente Jazz Metropolis sugere uma oposição ao 'modelo tradicional' de cidade, construída pelo teorema da modernidade enquanto variável independente e autônoma. Esta metáfora sintetiza uma outra alternativa de cidade, construída por um novo território permeável à improvisação, à elasticidade, às forças não programáveis, à espontaneidade de natureza social, de mercado e cultura, capazes de alterar continuamente a fisionomia e natureza deste território.

O cenário que emerge desta reflexão propõe a identificação de novos horizontes e desafios de interpretação pelo Design, com a sociedade, com sistemas e subsistemas que no interior da cidade se relacionam de forma independente do vazio, ou seja, um exercício de fazer cidade sempre aberto dedicado à natureza inconstante do domínio do mercado, permitindo liderança, inteligência e interatividade do 'utente'.

As condições de uma relação espontânea de mercado exigem cada vez mais à cidade uma condição de interação compulsiva com os sistemas de artefatos, em um processo dialógico, interativo e elástico. 
Este é um desafio para uma possível abordagem multidisciplinar no âmbito do projeto nas suas diferentes escalas, promovendo assim uma aproximação entre Design e a cultura de fazer cidade.

No século XXI, ao confrontarmo-nos com o DNA da cidade abandonada, é possível compreender que este tecido se rege sobre denominadores comuns segundo a necessidade de uma interação soft. Tornou-se emergente a ruptura com o exercício da tipologia tradicionalmente atuante no âmbito do projeto tradicional aplicado à refuncionalização, ou seja, um conflito que carece de novas abordagens disciplinares relacionais e de novas relações possíveis e aplicadas ao funcionamento de uma cidade que se deseja sustentável.

Este olhar constrói um quadro consciente e avançado dedicado às ideologias na história do Design, que são chamadas (pontualmente) a interagir com a cidade informal do século XXI.

Jazz Metropolis interioriza assim um espaço de síntese dedicado à ideia de fazer 'cidade', que se constrói segundo um sistema autorregenerativo, complexo e informal. À imagem do $j a z z$, veículo da improvisação integral para uma nova sonoridade - nos anos 1960 - Jazz Metropolis é a metáfora emblemática para evidenciar uma nova ordem na 'cidade', que, e como resultado, manifesta a natureza de um novo funcionamento em jazz; uma 'Cidade' irreverente, que rompe com as ideologias e estratégias de controlo disciplinar - o projeto - que outrora atuavam segundo princípios ortodoxos predefinidos como os implícitos na Carta de Atenas de 1933.

Com Jazz Metropolis reforça-se a ideia de uma metrópole partidária e permeável a uma improvisação integral em que, e para além das forças de natureza econômica e de mercado, outros elementos de ordem social se tornam preponderantes na alteração da fisionomia da própria cidade.

Com esta metáfora será possível sintetizar a imagem de todas as cidades permissíveis a uma nova instrumentalidade, nomeadamente aquelas que se encontram em forte crise de funcionamento. Refiro-me às cidades onde a crise imobiliária representa uma grande oportunidade no processo de reuso adaptativo. É neste contexto que nasce a ideia de jazz em um oportuno diálogo com Metropolis! Esta é a cidade cujo DNA é resiliente, elástico e flexível e que converte o problema do abandono em uma grande oportunidade através da integração de fenômenos sociais participados, integrando forças de natureza social, econômica e cultural.

Como no $j a z z$, a espontaneidade surge como um valor absoluto e ambicionado na arquitetura e no urbanismo. O peso desta variável era já uma evidência no $8^{\circ}$ Congresso Internacional da Arquitetura Moderna (CIAM8). Neste encontro Le Corbusier, ao referir-se particularmente às cidades latinas, indicava a espontaneidade como um valor vital incontrolável pela ambição do projeto moderno. 


\section{As formas do abandono}

Será fundamental ativar uma referência dos anos 1950, década na qual foi possível assistir às primeiras formas de abandono que abrangeu a indústria. Referimo-nos a realidades nas quais a força operária foi substituída pela automação integrada na cadeia produtiva que, na sua última estância, nos anos 1970, originou a revolução eletrônica alimentada pelos designados sistemas de "automação recursiva" (GALLINO, 1998). Enquanto a reorganização do processo produtivo iniciava o caminho de independência e controlo, Bell anunciava o redirecionar da força social e produtiva para um novo setor, que intitulou como The coming of post-industrial society (1973).

Tendo como objetivo uma aproximação ao momento de forte transformação do uso do território, propõe-se um outro salto na história, agora focalizado nos anos 1990. De acordo Roland Robertson, vivemos a "fase de incerteza da Globalização", das autoestradas digitais, possibilitando uma profunda transformação tecnológica que alimentou o próprio avanço da tecnologia da informação. O planeta sofreu uma rápida e acelerada transformação mundial face à deslocalização dos serviços e da força produtiva. A dependência do binômio tempo e espaço dissolveu-se (FRIEDMAN, 2005), proporcionando uma nova geografia produtiva à escala mundial organizada em função dos baixos custos de produção, assim como a reorganização dos serviços. O setor dos serviços, outrora condensado em edifícios verticais, com as autoestradas digitais dispersaram-se pelo território à escala mundial. O evento da globalização abriu assim o caminho para o conceito de "cidade global" enquanto produto de uma network, resultando em uma nova geografia de centralidade (SASSEN, 2003). Tóquio tornou-se uma evidência neste processo de abandono compulsivo. A cidade denuncia o ano de 2003 como "2003 problem", contabilizando o valor correspondente a 2,27 milhões de metros quadrados ${ }^{1}$ de edifícios do setor terciário abandonados. Neste contexto é fundamental referir a cidade de Londres que, no mesmo ano, apresentava o valor correspondente a 4,73 milhões de metros quadrados edificados e abandonados (PEREIRA, 2004). Itália, no setor industrial e de serviços, apresentava valores dispersos entre os quais é possível quantificar a área correspondente a 3 mil hectares apenas no setor industrial (DANSERO, 1993). Portugal, no ano de 2005, reconhecia a existência de 3,3 milhões de metros quadrados no mesmo setor (RIBEIRO,

1 Dados colhidos com base na entrevista com Prof. Matsumura, Universidade de Tóquio (Junho, 2006) 
2005), para além dos casos emblemáticos de metrópoles como Nova York, São Paulo e Argentina. ${ }^{2}$

\section{Um manifesto entre Design e Cidade na cultura do Adapting Reuse}

Em Os sete Palácios celestes de Anselm Kifer (Figura 1) é possível compreender a relação de dependência vibrante entre estas duas variáveis - sustentabilidade e adapting reuse. O valor da obsolescência cria o manifesto de uma cidade que se regenera em si mesma, em uma evolução contínua, sem um fim, através da sua própria matéria.

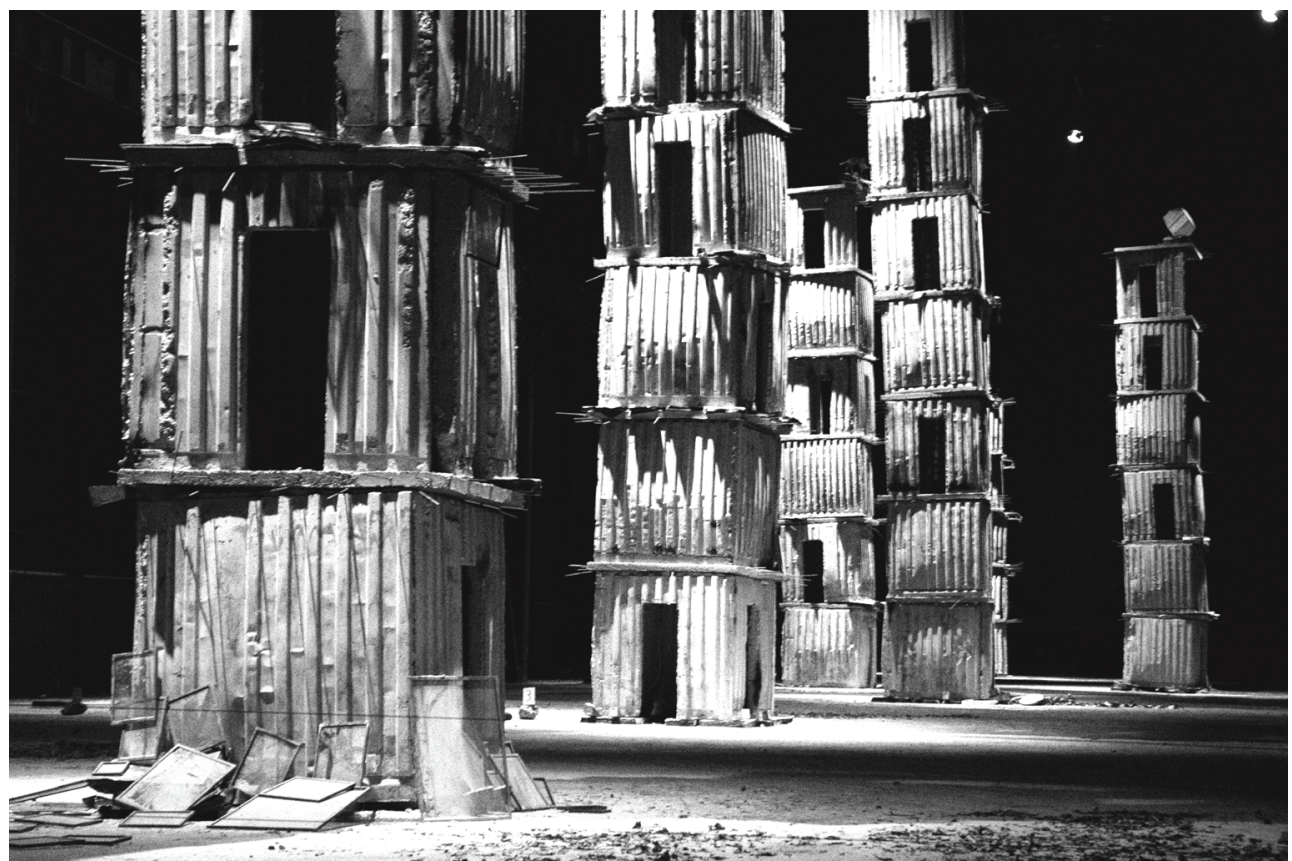

Figura 1 Instalação "I Sette Palazzi Celesti", Anselm Kiefer, Hangar Bicocca, Milão, Itália.

Fonte: Rui Roda.

A instalação, pela sua natureza regenerativa, serve de chave interpretativa à valorização do reuso como um valor sustentável à própria cidade. Os Sete Palácios celestes de Anselm Kiefer oferecem uma analogia com a mercadologia, re-

2 Os dados relativos às cidades indicadas podem ser observados em tese de dissertação realizada pelo autor (RODA, 2007, p. 47-63) 
correndo a peças modulares que se repetem e se empilham versus o infinito, uma espécie de elogio à flexibilidade que se torna independente ao espaço que ocupam, ao vazio. Este é um verdadeiro manifesto que desafia hoje um diálogo pertinente de uma cultura de fazer Design e a forma de regenerar a cidade no século XXI. Esta realidade exige um novo posicionamento à cultura do adapting reuse, à forma de regenerar a cidade em um processo continuo.

Em analogia com "out of control” de Kevin Kelly (1994), será possível sintetizar que as cidades se encontram em um estado de depressão permanente, procurando continuamente o seu estado de sobrevivência, e assim definindo um novo estado da 'biologia' da máquina entendida aqui como 'a cidade' que em jazz cria a evolução para uma nova sonoridade que envolve de forma determinante os sistemas sociais e a economia global.

Como reforço da perspectiva de reuso, orientado a um diálogo sustentável para a cidade, torna-se oportuna a identificação de uma economia que se alimenta da própria crise, a qual Storm Cunningham denominou de Restauration Economy. Estas duas dimensões, uma relacionada com o estado permanente de sobrevivência e a outra que assume uma analogia com a economia da crise, em comum, favorecem a importância da mutação como um valor ao ser aplicado à cidade. Esta realidade convida-nos a retomar um olhar sobre "a imagem da cidade" de Kevin Lynch (1960); uma cidade compreendida como uma tentativa contínua de erros e de fracassos, relativamente aos quais os edifícios se tornam resistentes a novos significados. Em um encadeamento de autores e, promovendo o sentido de uma cidade sustentável, Lewis Mumford, no seu clássico livro de 1961 - A cidade na história - suas origens, transformações perspectivas -, reforça o sentido deste movimento vital à própria cidade, assumindo-se também como fundamental a complexidade resultante da mistura de diferentes funções, ou seja, um verdadeiro valor para a vida das cidades, curialmente sustentado no mesmo ano em Morte e vida das grandes cidades por Jane Jacobs.

Em comum estas visões ratificam uma reflexão sobre a cidade que hoje se regenera dentro versus fora, por vezes, ausente de qualquer controlo dos gestores do território, gerando valor através da própria ' $a c ̧ a ̃ o$ '. Tornar-se-á pertinente assumir uma aproximação dialógica do $A D N$ do Design, agora dedicado ao exercício da refuncionalização da cidade, usufruindo assim da sua cultura de projeto da sua visão antropológica em diálogos multidisciplinares.

\section{Inputs Bottom-up que dinamizam o território urbano}

Não se pretende julgar o espaço da informalidade conotado negativamente como o lugar da desordem urbana e simultaneamente como espaço de entropia susceptível de múltiplas discussões disciplinares. 
Pretende-se, sim, dar ênfase ao lado positivo da regeneração informal, que contrai valores proativos liderados por grupos criativos, suscetíveis de delinear possíveis formas de inovação.

Torna-se pertinente um olhar panorâmico de evidências, presentes ao longo da história da regeneração urbana, no sentido de construir um percurso mental sensível a um recorte de observação cruzada dos casos, que permita identificar as ações informais da sociedade e seus impactos, por vezes integradas ou consolidadas pelas diferentes disciplinas que tendem a dar forma a estes inputs.

Igualmente importante será descodificar a natureza do utente, autor político disponível para o envolvimento com estes espaços informais. Pode-se observar que este utente, em uma primeira fase, fazia parte de uma natureza de criativos irreverentes; comunidades de artistas dos anos 1940 que se apropriavam informalmente das zonas desindustrializadas das cidades como Nova Iorque. A intervenção daqueles artistas no espaço urbano da cidade traduziu uma mudança radical na forma de habitar, ou seja, a sobreposição de funções do quotidiano concentradas em um único espaço. Esta realidade regenerou a cidade de Nova Iorque transformando-a em um bub reconhecido no final doas anos 1970 como centro mundial da arte contemporânea. Sharon Zukin, estudiosa deste processo evolutivo, assume estas experiências informais induzidas pelos laboratórios de artistas como um fato histórico na cultura do projeto para a cidade. A autora expressa: "So loft living rejects funcionalism, Le Corbusier, and the severe idealism form that modern architecture represents", (ZUKIN, 1989, p. 68).

Hoje, estes grupos são reconhecidos por comunidades criativas, fortemente familiarizadas com a tecnologia de informação e que Giuseppe Longo (2001) denominou de "bomo tecnologicus". Exalta-se assim estes grupos de utentes que interagem naturalmente com o reúso adaptativo urbano, para além de outras características já mencionadas, em uma primeira fase, nos anos 1940, obtendo a liderança nos processos independentes ao projeto formal, mas responsáveis pelas livres formas de ocupação através de soluções consideradas provisórias, não definitivas, sem pretensão de criar resultados rígidos. O surgimento desta nova interface - a produção de uma nova sonorização em jazz-com o espaço existente vazio construiu uma nova relação com o habitar, um novo 'modelo' que seguia uma direção completamente oposta à presente na primeira modernidade. Usando a analogia de Zygmunt Bauman, estes grupos de utentes integram-se nos que o autor chamou de "vagabundos", utentes irreverentes que se moviam fora da norma, das regras impostas pela sociedade. Com esta inovação social aplicada ao território, torna-se distintiva a regeneração das próprias leis, inicialmente obtusas, mas que, ao confrontarem-se com as ilegalidades destes grupos, regeneraram-se a si próprias no caminho da inovação e formalização de uma forma de uso ilegal, 
dando origem ao reconhecido "loftstyle" ou "loftliving" somente aceito no início da década de 1970.

Hoje, no século XXI, em uma perspectiva de recuperação destes valores, Tóquio e Osaka, na sua cultura de reuso adaptativo, assume uma relação de dependência com estes seres políticos - homo tecnologicus. Em ambas as cidades, mas especialmente em Osaka (distrito de Funaba, com a proposta Digital Box), é possível observar uma estratégia do governo para acionar o reuso de um inteiro quarteirão da cidade, em perfeita sintonia com grupos de utentes relacionados com a tecnologia de informação.

Torna-se simbólico, por parte do governo nipônico, o estímulo à regeneração destes espaços abandonados, aplicando a tipologia SOHO enquanto modelo 'funcionoide', que favorece a integração de uma multiplicidade de funções possíveis em perfeita ambiguidade induzida por uma intensidade tecnológica (open project). É também emblemática a aplicação desta tipologia em novos edifícios, tais como Shinonome e City Curt em Tokyo, entre outros.

Ao nível de uma leitura macro, evidencia-se a importância da cultura local do território que, através de uma natureza socioeconômica participada, torna emergente a valorização do território abandonado como uma oportunidade para gerar valor. Casos excêntricos deste contexto podem ser percebidos em algumas cidades. Milão, um centro mundial do Design, apresenta anualmente eventos que se manifestam usufruindo fortemente dos edifícios abandonados das ex-zonas industriais; no Rio de Janeiro, com o evento do Carnaval, é possível observar que, até ao ano 2006, a maior festa popular do mundo se confeccionava nos edifícios abandonados no porto da cidade; em Lisboa, com a sua refuncionalização provisória segundo a energia das designadas 'cidades criativas' - a LXFactory -, é possível identificar o reuso alternativo de espaços prestes a serem demolidos pelas forças imobiliárias; e, por fim, em Tóquio, com os eventos Tokyo Design Block (TDB) em simultâneo com Central Est Tokyo (CET), compreendemos esta manifestação com uma forte afinidade com instalação de artistas em concomitância com eventos que devém do Design.

\section{Design como energia implícita no processo de 'adapting reuso'}

Em comum são experiências que denunciam uma emergência dialógica entre a cidade e o Design em uma cultura de projeto. A conversão de edifícios ou de quarteirões, nos contextos apresentados, produzem mais-valias que nem sempre mantêm uma relação direta com a produção de riqueza. No entanto, em todos os casos, verifica-se que a relação de conversão produz um efeito benéfico na economia urbana daquelas cidades. 
A cidade visualizada por uma contínua reinterpretação dos seus espaços, induzida por grupos sociais criativos, produz, nesta reflexão, uma ideia de metrópole evolutiva em que a transferência e integração de valores de interação social alimenta a força de um motor energético da própria renovação. Esta poderá ser a ideia clara de uma cidade geradora de microexperiências intensas, mas sempre provisórias e 'imperfeitas', experiências de natureza informal lideradas pelos seus utentes, que, nesta análise, manifesta o poder de uma sociedade participativa. Através dos seus microinputs, geradores de possíveis habitares evolutivos, a metrópole contemporânea torna-se resistente à crise de funcionamento em que se encontra, contribuindo e assegurando, desta forma, o conceito de cidade que se regenera ao longo da sua própria história.

Esta energia social criativa abandona por completo os modelos pré-estabelecidos do habitar e interação com os espaços vazios da cidade. É neste sentido que o projeto, enquanto processo, e considerando a sua tradicional liderança, se confronta com uma certa fragilidade, sendo tendencialmente substituído pelo lugar do participante que vive a cidade, este último integrador e gestor da validade das suas próprias soluções. Como sinal embrionário desta fragilidade, torna-se pertinente relembrar o ano de 1952 na cidade de Hoddesdon, ano em que se celebrou o emblemático congresso internacional da arquitetura Moderna (CIAM 8) dedicado ao tema "O coração da cidade: em direção à humanização da vida urbana”. Este foi o momento decisivo para novos desafios que se colocavam ao mundo do projeto moderno, em que se especularam modos e seus limites ao se relacionarem com um tema tão desejado - "a espontaneidade". Ao seu tempo a espontaneidade é apontada como um valor na vida das cidades, um valor incontrolável tecnicamente pelo projeto.

Esta discussão denunciou, de alguma forma, o princípio da fratura entre arquitetura e o urbanismo moderno que, segundo Andrea Branzi (1999), funcionava segundo soluções definitivas, permanentes e perfeitas. $\mathrm{O}$ projeto moderno, enquanto abordagem à procura de soluções orientadas à sociedade, encontrou uma enorme fragilidade ao se julgar detentor da capacidade em determinar as necessidades do homem e de recriar a cultura urbana através da materialidade da cidade. Possivelmente será também este um dos contextos em que os formuladores do pensamento moderno iniciaram a sua trajetória rumo à crise da sua própria ideologia.

A Figura 2 ilustra o posicionamento do 'usuário' ambicionado pela modernidade, e também um novo posicionamento, ambicionado hoje pela pósmodernidade, do 'utente' ao deslocar-se para coparticipante nas soluções de projeto. Estes dois eixos constroem uma leitura possível na qual o eixo vertical pretende representar o espaço da participação do utente, e o eixo horizontal o espaço da flexibilidade. 


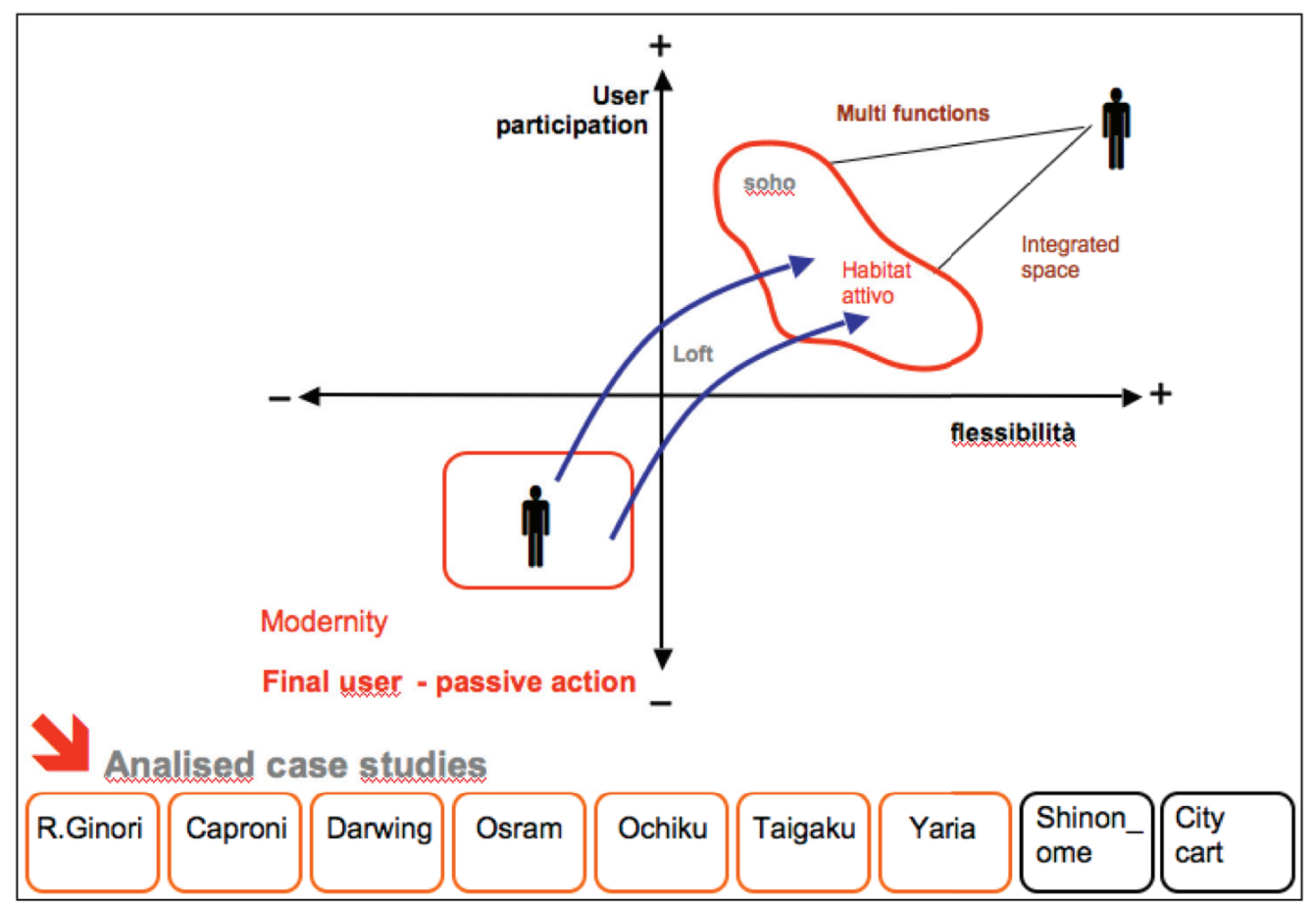

Figura 2 New Design Project Concept on reuse process.

Fonte: Roda (2007).

Desta forma, a relação disciplinar entre projeto e ciência, através da lente da metodologia, dissolve-se enquanto líder independente na procura de um resultado orientado ao usuário; na pós-modernidade, o utente final ocupa de forma tendencialmente crescente o lugar de destaque, como autor principal atuante que segue um guião intuitivo, mas improvisado e simultaneamente nutriente de seu próprio modelo de interação socioeconômica e cultural, na procura de alcançar as necessidades instantâneas.

Esta transferência de valores relacionados com a coparticipação do utente versus a procura de soluções espontâneas é representada no eixo horizontal e no sentido positivo da flexibilidade, uma qualidade gerida e estimulada pelo próprio utente. Neste cenário de mudança, é possível identificar a área na qual se torna indispensável a ação do Design, não no sentido de atuar diretamente na procura de soluções, mas no de potencializar e dar forma a processos que suportam soluções inovadoras 'desingenheirísticas', com base em uma abordagem de análise dos valores bottom-up estimulados por inputs sociais acionados por determinadas classes criativas, ou seja, uma geração de pensamento retomada no inicio do século XXI com Landry (2000), Florida (2002) e Howkins (2002), entre outros. 


\section{Considerações finais}

Como resultado da presente reflexão, torna-se fundamental o enquadramento do processo de reuso no contexto social da cidade contemporânea; uma forma de uso da cidade que, em si, manifesta valores e desafios emergentes para a construção de uma cidade sustentável. Neste sentido, torna-se pertinente abrir o debate aos desafios desta abordagem assim como os seus significados, ou seja, aos desafios deste diálogo entre duas escalas de ação (micro com o Design e macro com a Arquitetura e com o Urbanismo) que em si sugerem oportunidades implícitos às próprias disciplinas.

Tendo como objetivo proporcionar uma discussão disciplinar, destaca-se a mudança de uma ideologia do projeto enquanto processo; a passagem de paradigma a partir de uma visão na qual o homem abandona seu poder de adaptação face à presença de um modelo pré-estabelecido (modelo no qual seu briefing era invariável), para um novo momento em que é exigida a sua participação na procura de soluções que alimentam uma condição de permanente e acelerada adaptação - adapting - às suas própria necessidades - open project. Estes são hoje desafios que surgem como inquietações à própria disciplina de Design no século XXI, ou seja, um novo posicionamento à processualidade do próprio projeto, à própria pesquisa em Design que agora se coloca porosa à natureza do homem, alicerçando-o na forma como expressa a sua criatividade (SANDERS, 2004).

Esta abordagem promove a capacidade regenerativa da própria arquitetura, ou seja, uma arquitetura entendida como inteligente, capaz de se reconectar continuamente a novos contextos sociais e tecnológicos (BEGUINOT, 1998). Este desafio resgata uma visão já ambicionada por Adolf Loos, na qual visionava o desejo da arquitetura como um conjunto de mundos possíveis sitônicos e agregados, hoje manifestamente dependentes das ações bottom-up.

\section{Referências}

BAUMAN, Z. La società dell’incertezza. Bologna: Il Molino, 1999.

. Liquid Modernity. Oxford: Polity Press, 2000.

BEGUINOT, C. L'arquitettura è intelligente se è capace di (inter) connettere. Telema, v. 15, Inverno, 1998.

BELL, D. The coming of Post-Industrial Society. New York: Ed. Basic Books, 1973.

BRANZI, A. Design Italiano. Una Modernità incompleta. Milano: Baldini \& Castaldi, 1999. 
CUNNINGHAM, S. The Restoration Economy - The greatest new growth frontier. San Francisco: Berret-Koehler, 2002.

DANSERO, E. Dentro ai Vuoti. Dismissione industriale e transformazioni urbane a Torino. Torino: Libreria Cortina, 1993.

FLORIDA, R. The the rise of the Creative Class. New York: Basic Books, 2002. . The Flight of the Creative Class. New York: Harpe Business, 2005.

FRIEDMAN, T. The World is Flat. London: Penguin, 2005.

GALLINO, L. Se tre milioni vi sembran pochi. Sui modi per combattere la disoccupazione. Torino: Einaudi, 1998.

HOWKINS, J. The Creative Economy. London: Penguin, 2002.

IIID EXPERT FORUM FOR KNOWLEDGE. 2004. Preparing for the Future of Knowledge Presentation [video]. Disponível em: <http://www.knowledgepresentation.org/BuildingTheFuture/Summaries/Sanders_summary/SandersQuicktime/SandersMovie.html>. Acesso em: 22 maio 2007.

JACOBS, J. The death and life of great american cities. New York: Vintage, 1989.

KELLY, K. Out of Control. La nuova biologia delle machine, dei sistemi sociali e dell'economia globale. Milano: URRA, 1994.

KOSTELANETZ, R. SoHo. The rise and Fall of an Artists' Colony. New York: Routledge, 2003.

LANDRY, C. Creative City. A Toolkit for Urban Innovaitors. London: Earthscan, 2000.

LONGO, G. Nasce l'homo technologicus facciamo che sia anche umano. Telema, v. 24, Primavera, 2001.

LONGO, G. Il Simbionte. Prove di umanità futura. Roma: Meltemi, 2003.

LYNCH, K. A imagem da cidade. Lisboa: Edições 70, 1988.

MONTANER, J. A Modernidade Superada. Barcelona: GG, 1997. 
MUMFORD, E. The CIAM Discourse on Urbanism, 1928-1960. Cambridge, MA: MIT Press, 2000.

MUMFORD, L. A cidade na história: suas origens, desenvolvimento e perspectivas. São Paulo: Martins Fontes, 1982.

PEREIRA. M. Conversion of Buildings in New York \& London: Planning, politics, profitability and preference. Tokyo, Doctoral Thesis presented at Graduate School of Engineering, Department of Architecture, The University of Tokyo, 16 dez. 2004.

RIFKIN, J. The end of work. New York: Tarcher Penguin, 1996.

. L'era dell'accesso. La rivoluzione della new economy. Milão: Mondadori, 2000.

ROBERTSON, R. Mappare la condizione globale: la Globalizzazione come concetto centrale. Roma: SEAM, 1996.

RODA, R. Design to reuse abandoned buildings. Enabling flexibility and connection in the contemporary metropolis. Milan, Doctoral Thesis. Programme in Industrial Design - INDACO Department, Faculty of Design, Politecnico di Milano, Milan, mar. 2003 - abr. 2007.

SASSEN, S. Globalizzati e Scontenti. Milano: Saggiatore, 2002.

. Le città nell'economia globale. Bologna: Il Mulino, 2003.

SHIMURA, A. Current situation of area. In KOBAYASHI, S. (Org.). Renovation of district through SOHO conversion. Kyoto: Gakugei, 2005. pp. 88-95.

SIMPSON, C. SoHo. The Artist in the City. Chicago: University of Chicago Press, 1981.

ZUKIN, S. Loft Living. Culture and capital in Urban Change. New Jersey: Rutgers University Press, 1982.

. The creation of a "Loft Lifestyle". Lotus International, n. 66, p. 17-28, 1990. 